\title{
Influência de óleos essenciais no desenvolvimento de escleródios de Sclerotinia sclerotiorum (Lib.) de Bary, agente causal da Podridão Branca da Haste da Soja
}



${ }^{1}$ Mestranda em Biotecnologia, Programa de Pós-Graduação em Biotecnologia, Universidade Tecnológica Federal do Paraná- UTFPR/Campus Dois Vizinhos, Estr. para Boa Esperança, km 04 - Zona Rural, Dois Vizinhos - PR, Cep. 85660-000, Brasil. ${ }^{2}$ Doutoranda em Agronomia, Programa de Pós-Graduação em Agronomia, Universidade Tecnológica Federal do Paraná- UTFPR/Campus Pato Branco, Via do Conhecimento, s/n - KM 01 - Fraron, Pato Branco - PR, Cep. 85503-390, Brasil. ${ }^{3}$ Professora Adjunta, Universidade Tecnológica Federal do Paraná- UTFPR/Campus Dois Vizinhos, Estr. para Boa Esperança, km 04 - Zona Rural, Dois Vizinhos - PR, Cep. 85660-000, Brasil.

Autor para correspondência: Maristela dos Santos Rey (maris_rey@yahoo.com.br)

Data de chegada: 21/10/2017. Aceito para publicação em: 07/05/2018.

$10.1590 / 0100-5405 / 186890$

O fungo Sclerotinia sclerotiorum (Lib.) de Bary é considerado um dos patógenos mais importantes no mundo e está distribuído em todas as regiões produtoras, sejam elas temperadas, subtropicais ou tropicais. Os escleródios, responsáveis pela disseminação da doença, desempenham papel importante no ciclo de vida de $S$. sclerotiorum, visto que são precursores dos apotécios (ascocarpos), onde são formados os ascósporos (2). O controle da doença é baseado no manejo cultural, de forma a reduzir o potencial de inóculo, uma vez que, por se tratar de um patógeno de solo, o uso de fungicidas químicos, além de dispendioso, não apresenta resultados satisfatórios (1). A partir do exposto, o estudo objetivou verificar o potencial dos óleos essenciais de Syzygium aromaticum (L.) Merrill \& Perry, Eucalyptus citriodora Hook, Thymus vulgaris (L), Cinnamomum camphora (L.) Nees \& Eberm, Citrus reticulata Blanco, Melaleuca alternifolia Cheel, Cymbopogon citratus (DC) Stapf, Schinus terebinthifolia Raddi, Psidium guajava Linn,
Eugenia uniflora L, Casearia sylvestris Sw, Artemisia camphorata Vill, Citrus latifolia Tanaka, Cyperus articulatus L., Cinnamomum zeylanicum Blume, Zingiber officinale Roscoe e Citrus sinensis L, como possíveis antifúngicos, contra o patógeno S. sclerotiorum. O experimento, cujos resultados encontram-se na Tabela 1, foi realizado no Laboratório de Fitopatologia da Universidade Tecnológica Federal do Paraná. O inóculo original foi retirado de sementes de soja. Os óleos, em uma concentração de $15 \mu \mathrm{L}$, foram embebidos em fitas de papel absorvente de $1,0 \mathrm{~cm}^{2} \mathrm{com}$ auxilio de uma micropipeta, e fixados na tampa das placas de Petri, que continham um disco de 5,0 mm de micélio crescido em meio BDA (Batata-Dextrose-Ágar). Para a testemunha, utilizou-se no papel, água destilada esterilizada. As placas, devidamente vedadas, foram mantidas em câmara de crescimento do tipo BOD, sob temperatura de $24+$ ou $-1^{\circ} \mathrm{C}$ e fotoperíodo de 12 horas por 15 dias. A inibição da formação de escleródios foi calculada com

Tabela 1- Influência dos óleos essenciais no número e tamanho ( $\mathrm{mm}$ ) de escleródios de Sclerotinia sclerotiorum. Dois Vizinhos, 2017.

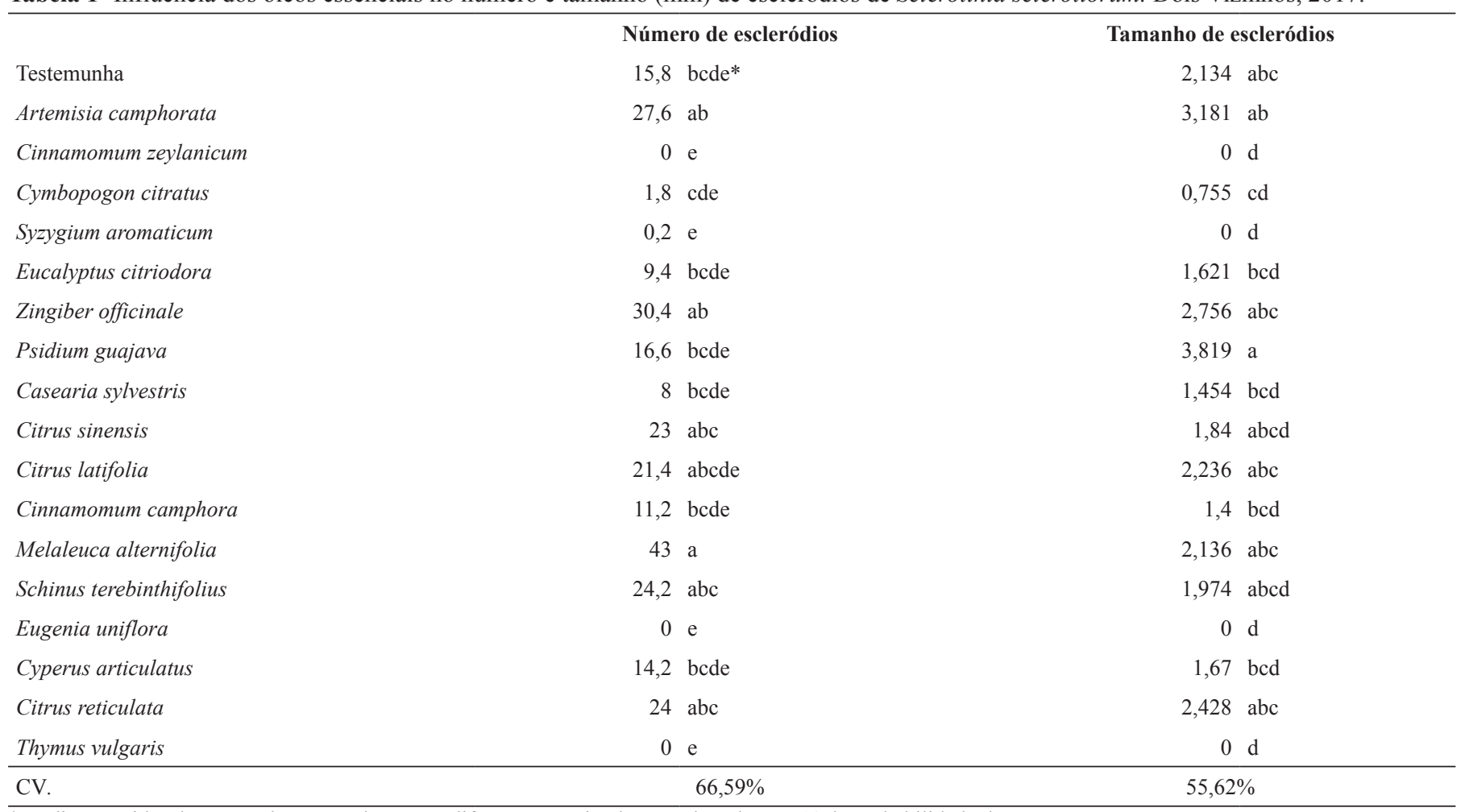

*Médias seguidas de mesma letra na coluna, não diferem entre si pelo teste de Tukey a $5 \%$ de probabilidade de erro. 
base na contagem dos mesmos durante os quinze dias de avaliação do experimento, sendo que, no último dia, os escleródios obtiveram sua área total mensurada em milímetros com auxílio de paquímetro digital. Os dados foram submetidos à análise da variância pelo teste de Bartlett quanto a homogeneidade. Às variáveis, cujas variâncias mostraram-se homogêneas tiveram os tratamentos avaliados pelo teste de Tukey a $5 \%$ de probabilidade. Para análise dos dados, foi utilizado programa estatístico R. Segundo os resultados, os óleos essenciais de Cinamomum zeylanicum, Cymbopogonn citratus, Syzigium aromaticum, Eugenia uniflora e Thymus vulgaris apresentaram número de escleródios menores, porém, não diferentes estatisticamente dos formados pela testemunha. Entretanto, os óleos essenciais de Cynamommum zeylanicum, Syzigium aromaticum, Eugenia uniflora e Thymus vulgaris por sua vez, apresentaram tamanho médio de escleródio igual a zero e diferentes da testemunha, evidenciando assim, o melhor controle do patógeno. Os óleos essenciais permitem que ocorra, devido a sua capacidade de repelir água, alterações nos lipídeos da parede celular, membrana plasmática e mitocôndria, causando alterações nestas estruturas (3). As informações obtidas através deste trabalho demonstram a importância de conhecer o efeito de tratamentos alternativos, auxiliando no entendimento da epidemiologia e suporte para produção de novos produtos naturais de controle da podridão branca da haste da soja.

\section{REFERÊNCIAS}

1. Campanhola, C.; Bettiol, W. Métodos alternativos de controle fitossanitário. Jaguariúna: Embrapa Meio Ambiente, 2003.

2. Juliatti, F.C.; Rezende, A.A.; Caires, A.M.; Aguiar, P.; Carneiro, L.M.S. Diferentes manejos no controle da podridão branca da haste da soja (Sclerotinia sclerotiorum). In: XXXI Reunião de Pesquisa de Soja da Região Central do Brasil, 2010, Brasília. Anais. Brasília, DF: Embrapa Soja, 2010. p. 1-321.

3. Zambonelli, A.; D'Aulerio, A.Z.; Bianchi, A.; Albasini, A. Effects of essential oils on phytopathogenic fungi in vitro. Journal of Phytopathology, New Jersey v.144, p.491-494, 1996. 